\title{
Stability of Photoch romism in New Bifunctional Copolymers Containing Spiropyran and Chalcone Moiety in the Side Chain
}

\author{
Dong Hoon Choi,' Si Young Ban, and Jae Hong Kim \\ College of Environmen and Applied Chemisty, Institute of Natmal Sciences. Kymg Hee Lniversity, Sanvon f49-70I, Nored \\ Received Alughst 13,2002
}

\begin{abstract}
We synthesised three copolymers beaning photechromic spirepy ran dye and chalcone moiety in the side chain for study ing the dy namic properties of their photechromism. They contain methacy late-spiropyran (MAspirepyran) and methacrylate-chalcone (MA-chalcone) w ith the different concentration. The photosensitivity of the new y sy nhesized copolymers was investigated by using UV-Vis atsorption spectroseopy. We obxerved photodimerization and photochromic hehavior under IVV irradiation at the same time. The eflect of photocrosslink on the rate and stability of photexhromism in three copolymers was considered in this study. This study might be helplul to design photochromie materials for irreversible optical memory by virtue of photocrosslinking reaction.
\end{abstract}

Key Words : l'hotochromic, Chalcone, spiropyran, Copolymer, l'hotocrosslink

\section{Introduction}

Polymeric materials have recently received much interest as photoreactive materials. ${ }^{1-1}$ Among many kinds of photoreactive matcrials. especially, photochromic compounds have attracted much attention because of their potential ability for various photoactive devices. such as oplical memory system. display device. oplic. and electro-optic component. ${ }^{5-9}$ Despitc many advantages of photochromic materials. one of the prime reasons lacking industrial applications of the photochromic materials. particularly organic photochromic compounds. is their poor stability of photochromism. "Although the extensive study on improving the durability of photochromic propery in many dyes was performed. the stable compound still remains rather limiled in practical applications.

On the olher land. spiropy rans and spirooxazincs are wellknown photochromic compounds. which undergo ring opening and E/Z-iransformation from the spiropy ran form to their corresponding merocyanine form by irradiation of UV light and vice versa by visible light or heat. ${ }^{1]}$ Since the merocyanine form is much different from the pristine spiropy ran moicty in their polarity and chemical structures. the colorization and decolorization process would be affected with micro-en ironmental condition. ${ }^{13.13}$

In order to improve the stability of photochromism in the polymer will spiropyran. pholocrosslink can be induced under irradiation of the same UV light source that is usually: utilized for pholochromism. In this work, we report that the kinclics of colorization and decolorization of the photochromic spiropyran dye could be affected by the concentration of the melhacrylate-chalcone (MA-clalcone) in the copolymer. The photoreaction property of chalcone-containing polymers was well-studied which revealed $[2 \pi+2 \pi]$ photocycloaddition in the film state ${ }^{1+15}$ Thus. the intennole-

\footnotetext{
"lo whom correspondence should be addressed: E-mail: dhehoi iakhuackr
}

cular pholocycloaddition of clalcone units in their copolyners can reduce the frec volume surrounding spiropy ran and merocyanine. which lower the rate of the photochromic process.

We have synthesized the photochemically bifunctional copolymers (BFCP-1. 2. 3) that contain spiropy ran and chalcone moictics as photochromic and photocrosslinkable unit in the side chain. respectively. This design is based on the premise that cach functional moicty could be sensitive photochemically and bchaves as a separated functional moicly at the similar wavelength region. The UV-Vis absorption spcciral analy sis and dy namic analy sis of photorcaction kinelies were carried out to craluate the efrect of the density of photodimerized clatcone moicties on the stability of photochromism in the copolymers.

\section{Experimental Section}

Synthesis. We followed the literature methods for sy nithesis of the compounds for the copolymers. ${ }^{16 .]^{-}}$The sy nthetic procedure of one copolymer was described herein as an cxample.

Synthesis of copolymer (BFCP-1) with MA-spiropyran, 1 and MA-chalcone, 2. The MA-spiropy ran ( 3 g. 7.2 mmole) and MA-chalcone $(0.702$ g. 2.4 mmole) were dissolyed in dried DMF $(17 \mathrm{~mL})$ in the presence of AIBN $(0.0084 \mathrm{~g}$. 0.048 mmole). The solution was $\mathrm{kepl}$ at $70^{\circ} \mathrm{C}$ for $48 \mathrm{hr}$ under argon atmosphere. Copolymer was collected and purificd by reprecipitation from DMF/methanol. The solid was reprecipitated wwice from ietralydrofuran/methanol until there was no monomer left and dried under vacuum at $90^{\circ} \mathrm{C}$ for 48 hr. Yicld. $79 \%$. $\mathrm{T}_{4} \sim 150^{\circ} \mathrm{C}$.

${ }^{1} \mathrm{H}-\mathrm{NMR}\left(\mathrm{CDCl}_{3}\right) \delta(\mathrm{ppm}) 1.10\left(+\mathrm{H} .2 \mathrm{x}^{\beta} \mathrm{CH}_{2}-\right) .1 .40-1.55$ (6H. $2 \mathrm{x}-\mathrm{CH}_{\mathrm{s}}$ in spiropyran unit). $2.25\left(6 \mathrm{H} .2 \mathrm{x}-{ }^{\alpha} \mathrm{CH}_{\mathrm{s}}\right) .3 .45$ $\left(2 \mathrm{H},-\mathrm{CH}_{2}-\right) .4 .05\left(2 \mathrm{H} .-\mathrm{CH}_{2}-\right) .5 .72(1 \mathrm{H} .-\mathrm{CH}=) .6 .25-8.05$ (6H. $\mathrm{H}$ in aromatic ring).

The other two copolymers (BFCP-2. BFCP-3) were prepared, 
following the same method above besides changing the feeding ratio of the monomer.

Film fahrication: For preparing the thin film, the solution (10 wt $\%$ ) of each copolymer in tetralỵdrofuran was filtered through acrodisc syrringe filter (Millipore $0.2 \mu \mathrm{ml}$ ) and then cast on the quartz plate. The film was dried ovenight at 80 ${ }^{\circ} \mathrm{C}$ under vacuum and it was quite helpful for removing a trace of color completely.

Instruments: UV-Vis absorption spectroscopic study was performed on a Hewlett Packard 8453 spectrophotometer (PDA type $\lambda=190-1100 \mathrm{~mm}$ ). All the films on quartz plates were irradiated with a $\mathrm{l} \mathrm{kW}$ high-pressure mercury lamp equipped with a liquid optical cable. Intensity of the UV light on the exposed surface was $1.15 \mathrm{~mW} / \mathrm{cm}^{2}(\lambda=250-390$ $\mathrm{nm})$, which was measured with a broadband power/energy meter model 13PEM00 I(MELLES GRIOT). For irradiation of visible light. we utilized He-Ne laser ( $\lambda=633 \mathrm{~nm} .6 .88$ $\mathrm{mW} / \mathrm{cm}^{2}$ ) for observing the decolorization behavior. For investigating the above two processes precisely, we setup the optical equipments as is shown in Figure 1.

The molecular weight was measured with gel permeation cliromatograplyy (GPC. Waters M616LC) using polysstyrene standard. The elemental analysis was performed with HP5890 GC clromatography: The themial belaviors of the copolymers were investigated by differential scaming calorimetry (DSC) using a Perkin Erlmer DSC7.

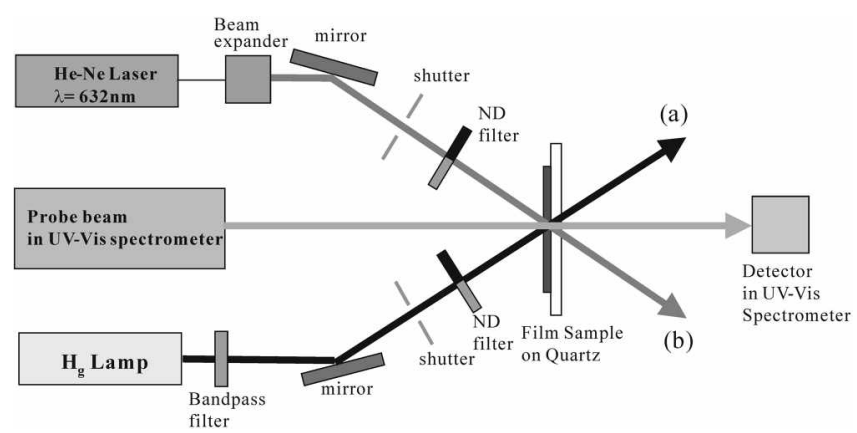

Figure 1. Optical setup lor investigating the photochromism of the copolyulet's.

\section{Results and Discussion}

Polymerization and properties. Bifunctional copolymers (BFCP) were synthesized by the radical polymerization of MA-spiropyran. 1 with MA-chalcone, 2 that can act as a photochromic unit and a photocrosslinkable one. respectively: The yields of polymerizations were relatively high around $79-85 \%$. Additionally: we also synthesized copolymer (MMA-CP) with MA-spiropy ran and methylmethacrylate (MMA) to compare the photochromic properties of bifunctional copoly mers.

The mole ratio of each component in copolymers wals determined with 'H-NMR spectroscopy and elemental andlysis. The monomer feeding ratios of MA-spiropyran and MA-chalcone were selected to be $3: 1,1: 1$, and $1: 3$ for BFCP-1. BFCP-2. and BFCP-3. The composition ratio of each monomer in the copolymers was quite similar to the monomer feeding ratio as is shown in Table 1 . The weight average molecular weight $\left(\mathrm{M}_{\mathrm{w}}\right)$ and glass transition temperature $\left(\mathrm{T}_{y}\right)$ were measured by the GPC and DSC. respectively: The molecular weights of three copolymers were in the range of 12300-21100. The glass transition temperatures of BFCP-1. BFCP-2. and BFCP-3 were 150. 134, and $125^{\circ} \mathrm{C}$. respectively. As the concentration of MA-spiropyran increases. the higher glass transition temperature was observed due to the bulkiness of the spiropy ran dye. Physical properties of the synthesized copoly mers were shown in Table 1 .

Absorption spectral analysis of photochromic copolymers. Functional copolymers containing spiropy ran moieties shows the photochromic properties both in their solution and in the film state. Figure 2 shows the absorption properties of the solution before and after irradiation of UV light. In Figure 2(A). solution spectra of three copolymers were illustrated before UV irradiation. The solutions having the same molar concentration of the polymer were taken for recording the absorption spectra. As the concentration of chalcone is higher, the absorbance at $313 \mathrm{~mm}$ is higher as we expected. However, if the absorbance at $313 \mathrm{~mm}$ is superimposed with the absorbance band of spiropyran dye in the simular

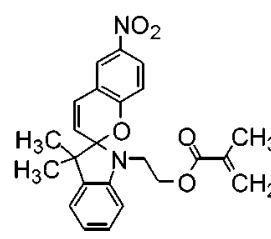

1

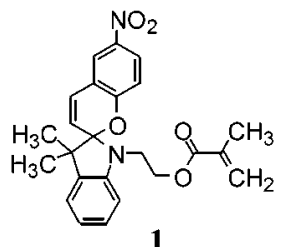

1

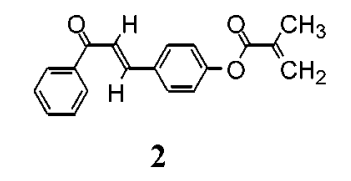

$\stackrel{\text { AIBN }}{\longrightarrow}$<smiles>CCC(C)=O</smiles>

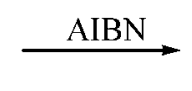

MMA

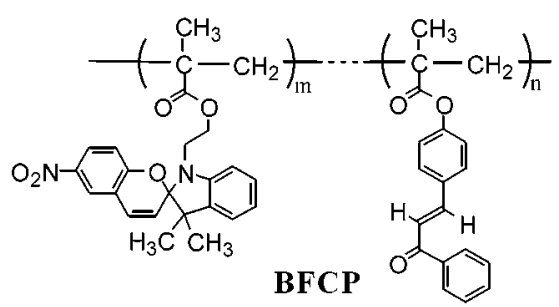

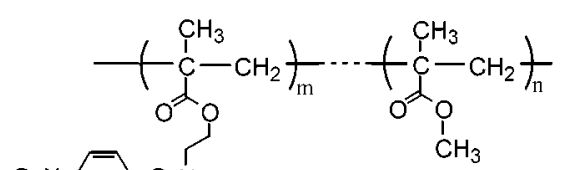

MMA-CP

$m: n=1: 1$

Scheme 1. Stutheses and structures of copolyulers used in this study. 
Table 1. Measured phy sical parameters of the copoly mers

\begin{tabular}{|c|c|c|c|c|c|c|c|c|c|}
\hline & & \multicolumn{2}{|c|}{ IBICCP-I } & \multicolumn{2}{|c|}{$\mathrm{I} 3 \mathrm{ICCP}-2$} & \multicolumn{2}{|c|}{$\mathrm{I} 3 \mathrm{H} \cdot \mathrm{C} \cdot \mathrm{P}-3$} & \multicolumn{2}{|c|}{$\mathrm{MMA}-\mathrm{CP}$} \\
\hline$T_{k}\left({ }^{\prime \prime} \mathrm{C}\right)$ & & \multicolumn{2}{|c|}{150} & \multicolumn{2}{|c|}{1.34} & \multicolumn{2}{|c|}{125} & \multicolumn{2}{|c|}{140} \\
\hline$H_{r}$ & & \multicolumn{2}{|c|}{18096} & \multicolumn{2}{|c|}{12348} & \multicolumn{2}{|c|}{21145} & \multicolumn{2}{|c|}{15416} \\
\hline \multicolumn{2}{|l|}{ Mole Ratio } & \multicolumn{2}{|c|}{$76.1: 23.9$} & \multicolumn{2}{|c|}{$44.4: 55.6$} & \multicolumn{2}{|c|}{$240: 760$} & \multicolumn{2}{|c|}{$48.7: 51.2^{b}$} \\
\hline \multirow{4}{*}{ lijemeutal $\Lambda$ ualy sis } & & Culed & Obsd & Caled & Ohsd & Caled & Ohsid & Caled & Obsid \\
\hline & C & 70.35 & 68.32 & 72.46 & 67.67 & 74.98 & 74.78 & 66.9 & 64.72 \\
\hline & $\mathrm{H}$ & 5.71 & 5.94 & 5.66 & 6.52 & 5.59 & 5.51 & 6.20 & 6.27 \\
\hline & $\mathrm{N}$ & 5.41 & 4.43 & 3.93 & 1.62 & 2.16 & 1.44 & 5.38 & 5.43 \\
\hline
\end{tabular}

"MA-spiropșran: $\mathrm{M} \wedge$-chalcone. "MA-spirops'rant: MMA.

absorption wavelength region, it will be difficult to expect the photochemical reaction of chalcone unit effectively. After UV irradiation. the spectral change is shown in Figure 2(B). This is quite reasonable in the copolymer containing ligher concentration of the photochromic dye. Figure 3 shows the absorption spectral changes of BFCP-1, 2. and 3 films during the UV irradiation at 250-390 $\mathrm{nm}$. The colorized form of spiropyran in the film state shows the absorption maximum at $586 \mathrm{~mm}$ in the beginuing stage, which proves mans-conformation of merocyanine cluromophore (see Scheme 2)

The $\pi \rightarrow \pi^{*}$ absorption band of merocyanine chromophore
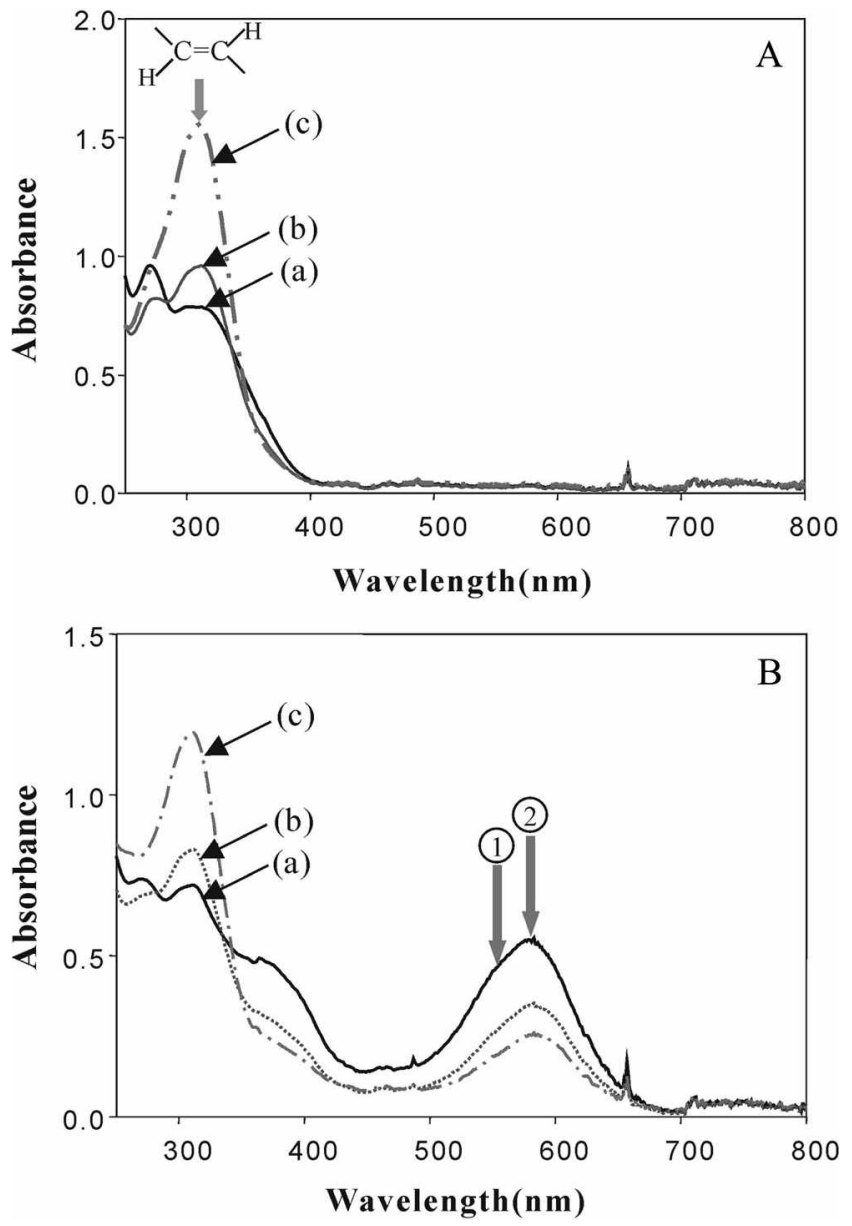

Figure 2. UV-Vis absorption spectral analysis of $\mathrm{BFCPs}$ during UV itradiation. (a) BFCP-1, (b) BFCP-2, (c) BFCP-3.
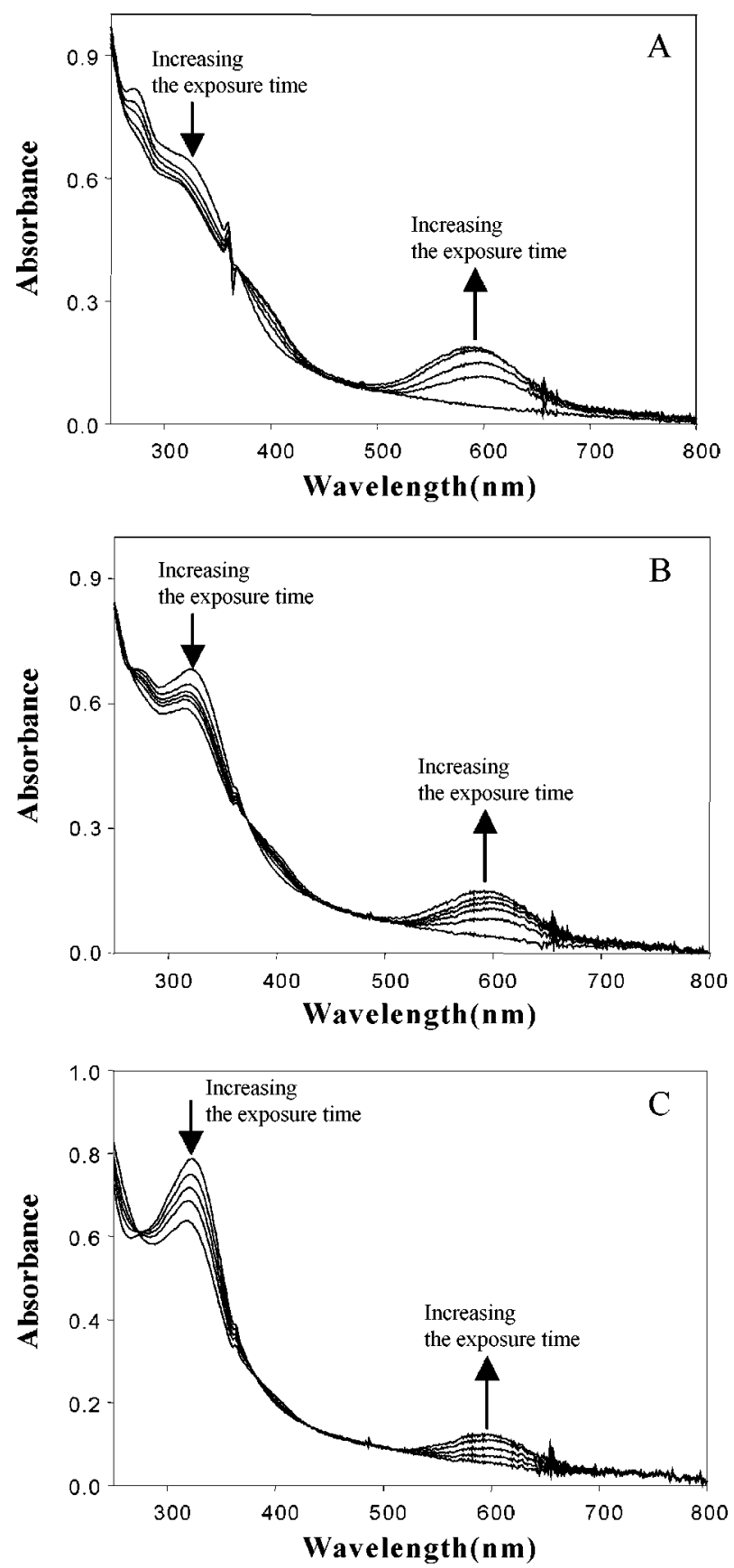

Figure 3. Change of absorption spectrum durimg irtadiation of UJV and visible light. (A) BlFCP-1, (B) BHCP-2 (C) BlFCP-3 film. 


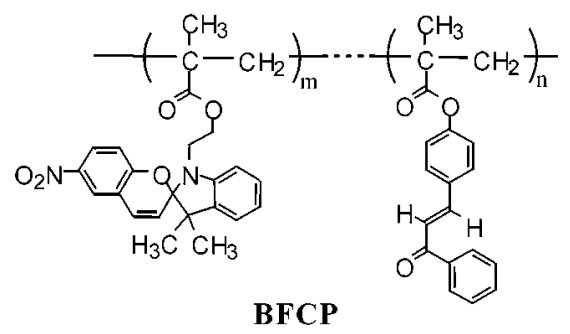

BFCP
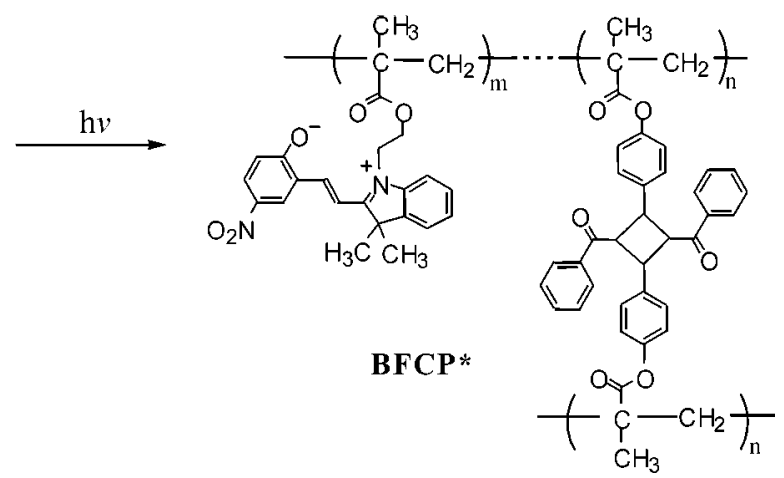

Scheme 2 . The transformed structure of the copolymer after UV irradiation.

from spiropy ran moiety at $586 \mathrm{~nm}$ increased gradually with the UV irradiation time. In the case of BFCPs film, the absorption band of the chalcone moiety $\left(\lambda_{\text {saia }}: 310 \mathrm{~nm}\right)$ decreased simultaneously with increase in the absorption intensity resulting from increase of the concentration of merocyanine dye. This means the disruption of double bond in chalcone group during colorization. The BFCP-3 (Figure 3C) showed higher absorbance at $310 \mathrm{~nm}$ due to higher concentration $(76 \%)$ of chalcone unit. By the $[2 \pi+2 \pi]$ photocycloaddition of chalcone moieties that can reduce the distance between polymer chains, the free volume surrounding the spiropyran unit. which is necessary for the photocolorization and decolorization process is expected to decrease significantly: The kinetic study of photochromism was conducted to evaluate the effect of photocrosslink on colorization and decolorization process, it depends on the concentration of chalcone moiety in the copolymer.

Kinetics of photochromism. The kinetic evaluation of photochromic process of BFCPs was carried out by the measurement of absorption change during irradiation under UV light $(\lambda=250-390 \mathrm{~nm}$ ) for the ring opening and $E / Z$ transformation and under He-Ne laser $(\lambda=632 \mathrm{~nm})$ for the ring closure reactions in the film state.

Rates of colorization of BFCPs were measured from change of the absorbance at $\lambda_{\text {ruax }}$ which were shown in Figure 4A. The intensity of irradiated UV light was 1.15 $\mathrm{mW} / \mathrm{cm}^{2}$ and rate constant was calculated by following the double exponential equation ( 1 ) shown below: ${ }^{\text {Is }}$

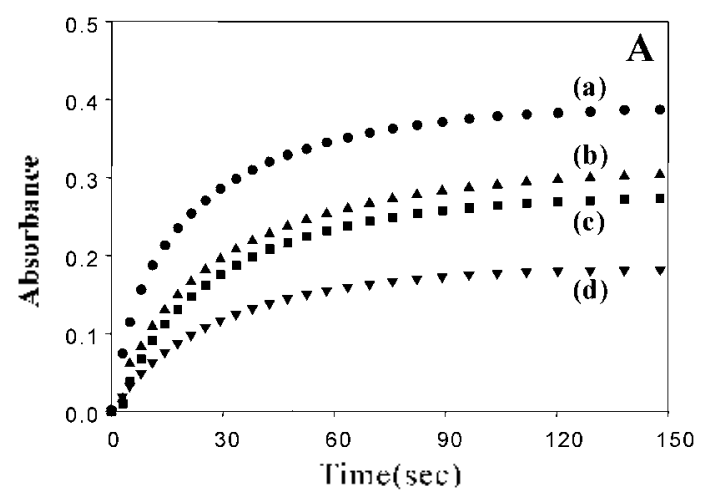

$$
A(t) / A(0)=A_{1}\left[1-\exp \left(-k_{1} l\right)\right]+A_{2}\left[1-\exp \left(-k_{2} t\right)\right]
$$

The rate of decolonization was also measured in the film state by following the decrease of the absorption band at $\lambda_{\text {tIus. }}$ and can be calculated using double exponential decay function (2) (see Figure 4 B). ${ }^{18}$

$$
A(t) / 1(0)=A_{3}+.1_{1} \mathrm{exp}\left(-k_{3} t\right)+.1 ; \operatorname{cxp}\left(-k_{t} t\right)
$$

In the colorization process, the BFCP-1 showed smaller rate constant, $k_{1}$ than BFCP-2 and BFCP-3 does.(See Table 2) This is likely to be affected by the higher concentration of the spiropy ran unit and higher glass transition temperature of the BFCP-1. ( $T_{g}$ of BFCP-1: $150^{\circ} \mathrm{C}$ ) As the concentration of the spiropy ran dye increases. the $E / Z$ transformation will be much more difficult to perform. In a later stage of colorization. we can also expect the effect of electrostatic interaction between the dyes. If the concentration of the merocyanine dye became larger. there would be a high degree of aggregation between the dyes themselves. Sometimes, the closed form of spiropyran dyes will be caged inside the aggregation. Additionally; we can confirm that the photocycloaddition between the chalcone groups may affect the dy namic behavior of photochromism in part since MMA-CP has the highest rate constant, $k$. But it is not so significant to compare with the effect on decolorization process.

In the photo-accelerated decolorization process. the rate constant $k_{3}$ of $\mathrm{BFCP}-3$ was slightly smaller than those of BFCP-I and BFCP-2. (See Table 2) MMA-CP showed the

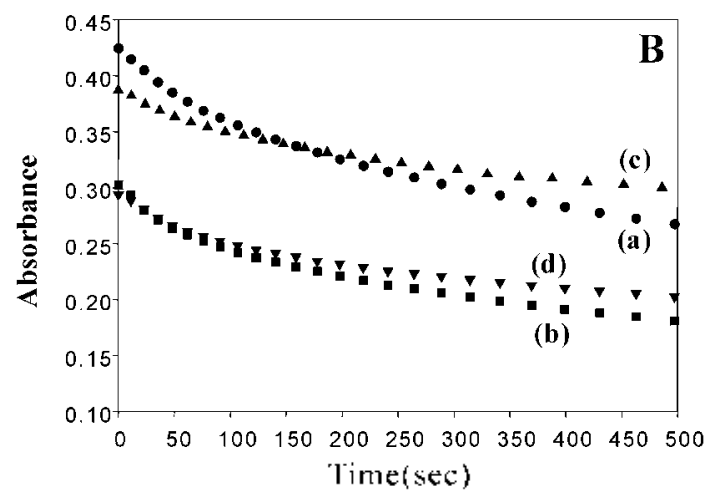

Figure 4. Dỵnamic bchavior of photochromism in colorization and decolorization as a function of time. A: Rising curves, B: Decaying curves. (a) MMA-CP, (b) Bl-CP-1, (c) Bl C CP-2, (d) Bl'CP-3. 
Table 2. Calculated paranneters from the dy namic behavior of photochromism in the copolymers

\begin{tabular}{|c|c|c|c|c|c|c|c|c|c|}
\hline & \multicolumn{4}{|c|}{ Rising Curve } & \multicolumn{5}{|c|}{ Decalying Curve } \\
\hline & $A I$ & $k_{1}$ & $A_{2}$ & $\mathrm{k}_{2}$ & $A s$ & $k 3$ & $A_{+}$ & $k+$ & $R$ \\
\hline BFCP-I & 0.1447 & 0.0501 & 0.1703 & 0.0166 & 0.0490 & 0.0115 & 0.1422 & 0.0012 & 0.1026 \\
\hline $\mathrm{BFCP}-2$ & 0.2226 & 0.0515 & 0.0603 & 0.0157 & 0.0371 & 0.0109 & 0.1 .387 & 0.0009 & 0.1909 \\
\hline $\mathrm{BFCP}-3$ & 0.0321 & 0.0949 & 0.1523 & 0.0285 & 0.0449 & 0.0107 & 0.0944 & 0.0011 & 0.1516 \\
\hline MMA-CP & 0.1447 & 0.1593 & 0.2456 & 0.0291 & 0.0650 & 0.0120 & 0.2098 & 0.0017 & 0.1477 \\
\hline
\end{tabular}

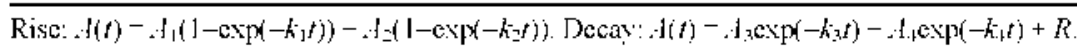

lighest decaying constant compared to the chalcone-containing copoly mers. It means that during the UV irradiation, photodimerization between the chalcone moieties reduced the distance between polymer chains and gave smaller free volume necessary for transforming from trans-merocyanine dye to the spiropy ran dye.

Although the concentration of the chalcone monomer in BFCP-3 is three fold of that of BFCP-1, the rate constants did not show significant difference. This can be explained as follows; In case of BFCP-l. we can think about the attractive electrostatic interaction between merocyanine dyes due to higher concentration of the spiropyran dye. However. in BFCP-3. the merocyanine dyes were not subject to strong electrostatic interaction because of the low concentration of the spiropyran dye. Therefore. we can consider the compensated effect between the electrostatic interaction and the geometrical hindrance. Shortly: it can be concluded that the effect of steric lindrance is dominant over the electrostatic interaction in this case.

Since in the condensed system of UV-irradiated sample. the molecular motion of the side chain is significantly limited to compare with that of guest-host system or thermoplastic copolymer. It could be saying that the ring closure reaction in BFCP film after UV irradiation is much retarded by increasing steric hindrances resulted from intermolecular photocycloaddition of chalcone units. This residual form of merocyanine in the film should be surrounded and entrapped by cyclobutane derivatives so that it could not have enough free volume for backward $Z / E$ transformation to the pristine form of spiropy ran dye.

We could control the rate of photochromic behavior of spiropyran in the film state by introducing the chalcone moiety in the copolymer somewhat so that it improved thermal stability of colored species.

\section{Conclusion}

The stability of photochromic property in spiropyran dye itself has been well known to be very poor. We synthesized new bifunctional copolymers (BFCPs) including photochromic spiropyran and photocrosslinkable chalcone moieties to improve the stability of chromism. The rate control of ring opening and ring closure reaction of spiropyran dye was successfully achieved by virtue of $[2 \pi+2 \pi]$ photocycloaddition between the chalcone units, which is expected to control the electrostatic interaction and steric hindrance surrounding photochromic moiety. As the concentration of chalcone moiety was higher in the copolymer, the stability of photochromism was found be somewhat better after UV irradiation although the difference is not significant.

Acknowledgement. This work was financially supported by the Korea Research Foundation (KRF-2001-005-D0(0)(04).

\section{References}

1. Sun. S.-J.: Schwarz. G.: Kricheldorl. H. R.: Chang. [I.C. J. Fohm. Sci. Pott.1: Folym Chem. 1999, 37(8), 1125.

2. Rehab, ^.: Salahuddin, N. Folvmer 1999, $+0(9), 2197$

3. Kawatzuki. N.: Yamamoto. T.: Ono, H. thpl. Phs. Left 1999. $74(7), 935$

4. Gong. Y.-K.: Nakanishi. F. the K. Hot. Cnst. Liq. Cnst. 1999. 327.123

5. (a) Matsuda. K.: Irie. M. J. Am. Chem. Soc: 2000. 122. 7195. Also sec (b) Matsuda, K.: Iric. M. Polyhedron 2001. 20. 1391. (c) Iric M. Chem Rev 2000. 100, 1685 .

6. (a) Tamaoki, N.: Keuren, F. V.: Matsuda. II. Appl Phys Iett. 1996. 69(9). 1188 . (b) Cullum. B. M.: Mobley. J.: Bogard. J. S: Moscovitch. M.: I'hillips. G. W: Vo-Dinh. 'I. Anal. Chem. 2000. 72. 5612 .

7. (a) Bobrowsh: A. Y.: Boiko, N. I.: Shibact. V. P. Liquid Crwials. 2000, 27. 57. And also see (b) 2000. 27, 219. (c) Sasaki. K.: Nagamura. T. .tppl. Phss Lett 1997. 71, 4.34.

8. Ock. K. S.: Jo. N. J.: Kim. J. H.: Kim. S. H.: Koh. K. N. Symthetic Hetal 2001. H7. 131.

9. (a) Jansson. R.: Zangoole. S.: Kuster. T.: Arwin. H. J. Phys. Chem of Soldd 2001. 62, 1219. (b) Ghailane, F.: Manivannan, G.: I.essard, R. A. Optical T.tig. $1995.34,480$.

10. Kim, S. HI.: I .ce, S. M.: Park, J. II.: Kim, J. II.: Koh, K. N.: Kang, S. W. Dyes and ligment 2000. 45.51.

11. Gömer. H. Chem. Phusics 1997. 222.315.

12. Goldburt E.: Shvartsman. F.: Fishmann. S.: Kronęauz. V. Nacomolecules 1984, 17. 1225 .

1.3. (a) 7.hou, J.: Sui. Q.: Iluang. B. I. Photoche'm. and Photohiol it Chem. 1998. 117. 129. (b) 7clichenok, A.: Buchuolt. Г.: Yitzchaik. S.: Ratner. J.: Safro. M.: Krongauz. V. Hacromolecules 1992. 25.3175

14. Choi. D. H.: Cha. Y. K. Bull Kowem Chem Soc. 2002. 23. 4.

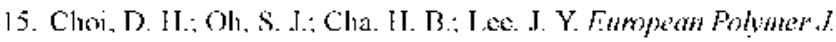
$2001,37,1951$

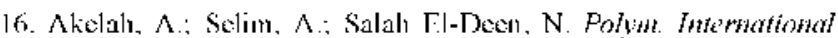
1992. 28. 307.

17. Akelah. A.: Selim. A.: Salah El-Deen. N. Polym. Intentaional 1993. 32. 423.

18. (a) Allookt, H. R.; Kim, C. H. Wacmolectle's 1991, 2t. 2846 (b) Bitcau, I.; Chaput, F; Boilot, I.-P. .l. Phys. ( $h k^{\prime} m$. 1996, to0, 9024 . 